\title{
Study on construction of teaching staff in competitive sports schools based on humanistic management
}

\author{
Bo ZHOU \\ Department of Police Skills and Tactics \\ Nanjing Forest Police College \\ Nanjing 210023, China \\ e-mail: zhoubo@nfpc.edu.cn
}

\author{
Fan ZHANG* \\ Department of Police Skills and Tactics \\ Nanjing Forest Police College \\ Nanjing 210023, China \\ e-mail: zhangfan@nfpc.edu.cn
}

\author{
Changzhi JIA \\ Department of Police Skills and Tactics \\ Nanjing Forest Police College \\ Nanjing 210023, China \\ e-mail: jiachangzhi@nfpc.edu.cn
}

\begin{abstract}
Humanistic management is in the pursuit of full development and utilization of human resources, to maximize the potential of people. Similarly, as the sports schools that cultivate excellent sports talents, the development of the teaching staff's potential abilities should be paid attention to. Besides, the teachers should also be regarded as the a kind of resource that can be developed and utilized, of which the training and development should be focused on. Based on the basic principles of construction, this study puts forward the main objectives and contents of the cultivation of high-quality teachers in sports schools. It is hoped that improving the teachers' ability can improve the quality of talent cultivation in sports schools and industry's competitive advantage, as well as promote the sustainable development of schools.
\end{abstract}

Keywords-humanistic management; sports schools; young athletes; teaching staff; management mechanism

\section{INTRODUCTION}

The quality of young athletes' training is quite dependent on the depth and precision of their education. As young athletes have both the identities of students and athletes, their education is derived from two channels which are teachers who teach cultural knowledge and coaches who teach sports skills. As two main educational carriers of sports schools (cultural teaching and sports training), the quality of education provided depends on whether the teachers (teachers and coaches) form good combination, and ultimately depends on their teaching abilities [1]. Since the teaching staff is the decisive factor of the quality and level of the humanistic quality education in sports schools, its status and function on the operation of sports schools have been recognized. Therefore, it is necessary to clarify the basic principles, main objectives and contents of the construction of the teaching staff.

\section{PRINCIPLES ShOUld Be Followed IN THE CONSTRUCTION OF High-Quality TEACHING StafF}

A. Focusing on the Innovation of Concept, Knowing the Direction for the Construction of Teaching Staff

First, the schools should always adhere to the combination of scientific concepts of work and friendly operational mode, the combination of orderly policies of work and comfortable atmosphere for learning and training, as well as the combination of meticulous work and daily teaching and training. Besides, the schools should also stick to the philosophy of "people-oriented, moral education comes first" and promote the popularity of humanistic quality education and all kinds of construction.

Second, the schools should adhere to the principles of close to reality, close to life and close to young athletes, based on the free and all-around development of young athletes and take the characteristics and reasonable demands of young athletes as the breakthrough points for the construction of the teaching staff. The schools should combine the construction as well as the practical problems in the humanistic quality education of young athletes and determine the working policies for studying and training as "guiding the teaching and training, forming the living habits, developing the interpersonal relationships and achieving the mental health" to achieve the goal of education [2].

Thirdly, the schools will strengthen the depth of education policy, operational strategy and other respects, and insist on the integrity of process, orientation and the students. The dynamic integration of "the two classrooms in class and out of class", "two places for training and not for training", as well as "teachers and coaches" should be achieved [3]. Besides, the humanistic quality education should be integrated into different processes of the learning of humanistic knowledge and the specialized training for young athletes to achieve the goals of "becoming human beings", "studying" and "training" in the process of culture learning 
and specialized training, to help young athletes truly establish the correct concepts of self-discipline and heteronomy.

\section{B. Focusing on Practice Results, Knowing the Scientific Nature of the Construction of Teaching Staff}

First, the principle of institutional means that in the process of culture teaching and sports training, the schools should always adhere to putting education in the first place, to establishing the policies with scientific means, to implementing the policies with standardized model so that the policies can be effectively implemented to make the policies with clear structure, strict system, and proper order. This is the internal requirement of the normal construction and operation of the teaching staff in sports schools, and also the inevitable trend of the construction of humanistic quality education in sports schools [4]. The principle of institutional should be taken as the principle of self-discipline by all teachers and coaches in the process of learning and training. They should also form the way of thinking and act that follows the institutional norm and consciously abides by the discipline.

Second, the principle of humanized means that the schools should adhere to the core concept of "peopleoriented" scientific outlook on development and take young athletes as the foundation of construction. The schools should also take "what kind of people to cultivate as" and "how to cultivate people" as the main task of the construction of the teaching staff and combine the young athletes' fundamental interests with the stable development of the back-up talent cultivation. Adhering to the principle of humanized is to take the young athletes' growth and development as the fundamental objective, and to tightly integrate teaching cultural knowledge, training athletic ability as well as improving the comprehensive quality of young athletes into their free and all-around development.

Third, the principle of scientific means that the schools should always take full account of the tradition and innovation, scientific nature and feasibility and other aspects, to establish the sustainable development policy. The construction of the teams of teachers and coaches should be better matched with the actual needs of sports school and the requirements of service, to ensure that young athletes can better develop with the promotion of high-quality teachers and coaches. The construction of the teaching staff should pay attention to the self-construction of the young athletes. Taking humanistic quality education as an opportunity, the teaching staff should make young athletes achieve selfevaluation and self-selection through self-knowledge and self-discovery, and build a platform for young athletes' growth.

Fourth, the principle of dynamic. The construction of the teaching staff should be taken as a dynamic system, which should focus on the strategic objectives of the sports schools. The schools should base on improving the quality of personnel training and follow the overall situation of the sports schools' development. Besides, they should sum up the experience and lessons in the construction and pay attention to feedback adjustments, to achieve the good combination of the principles and flexibility. The young athletes' reaction during the implementation of humanistic quality education should be understood and their suggestions and opinions should be considered. Then the schools should analyze and resolve the problems encountered in the process of implementation.

\section{OBJeCtives AND CONTENTS OF THE CONSTRUCTION OF THE TEACHING STAFF}

\section{A. Objectives of the Construction of the Teaching Staff}

1) With high level of humanistic knowledge and professional theory of training: Teachers and coaches should not only have the professional knowledge and high artistic appreciation, but also promote their humanistic spirit, emotion, attitude and values continuously. Therefore, they must have dynamic knowledge structure with multiple sequences, various elements and multiple levels. First the basic humanistic knowledge is the theoretical knowledge of humanistic quality education. Second, the knowledge of educational theory are how to be a good teacher (coach) and how to teach students (young athletes) the basic knowledge well. Third, the professional theoretical knowledge is the direction of teachers and coaches [5]. Fourth, the theories, kills and methods of tools subjects are the prerequisites for the realization and application of the combination of teachers who teach cultural knowledge and coaches who train specialized skills.

2) With strong ability to combine business and humanistic quality education: At present, when the humanistic quality education is promoted, the teachers' and coaches' objectives of ability and quality should include the following aspects. First, the ability to organize and coordinate is the important guarantee for teacher and coaches to do a good job in teaching and training. Teachers and coaches should be able to integrate their own humanistic spirits, humanistic qualities and sound values into the cultural knowledge teaching or specialized training. Second is the ability of scientific research. In sports schools, teachers who teach cultural knowledge and coaches who train specialized skills are mainly engaged in the combination of theoretical knowledge and sports training, so the only guarantee for the continuous improvement of the teachers who teach cultural knowledge and the coaches who train specialized skills as well as their business abilities and theories is scientific research. Third, the ability of creative thinking is an important part of teachers' and coaches' ability. Due to the particularity of teaching and training and the characteristics of the youth athletes, teachers and coaches are required to not only think independently, but also constantly explore new areas and take the lead to influence and motivate young athletes to acquire knowledge and sports skills in the process of forming sound outlook on life, values and world view. 


\section{B. Contents of the Construction of the Teaching Staff}

1) Establishing a flexible and diverse system of selection and employment: Sports school must establish a scientific, flexible and diverse system of selection and employment for the construction of teaching staff. First of all, the schools should take full advantage of the strong influence, the openness and many other advantages of the "market" [6]. They should know what type of talents they really need and try to attract high-level talents from a wider area and much more information. Driven by the market, the schools should ensure that the talents required by the sports schools can be met, and be promoted. Second, the schools should strengthen the "mechanism of talent introduction", and adhere to the diversification of the construction of teaching staff, including the development of school resources, the development of social resources and the development of international resources [7].The sports school should take the appointment system and the core of the system should be choosing the best talent for employment in the competitive mode. With the deepening of the appointment system and the integration of the resources and structure of the coaches and teachers, the schools can ensure that the scientific construction of the posts. Whether the appointment system can be implemented lies in whether the scientific nature and rationality of the job is in line with the standard. If the construction of posts is lack of scientific nature and rationality, then the appointment system is impossible to be implemented.

2) Establishing rigorous and orderly assessment procedures and the mechanism of promotion and incentives: In order to ensure the quality and reputation of the personnel training in sports schools and to establish high-level teaching staff, it is necessary to carry out the assessment, which should be carried out from the contents, reference standards, methods and steps. When the schools carry out assessment on the teachers who teach cultural knowledge and the coaches who train specialized skills, they should also take into account the moral, knowledge, ability and performance [8]. The so-called performance can be fully reflected in the abilities of the coaches or teachers in other three aspects so the assessment of performance should be focused on and strengthened. But the performance not only refers to the workload of teaching or training, how many papers published, how many teaching materials and works written, how many champions trained and how many records broken, but also includes the quality and level of teaching, educating, research and training. The schools should adopt the new system of promotion based on the performance assessment, namely "small step and continuous progress", making the long-term incentive system be more sound. Hence, the current model of lifelong promotion in the actual work environment of sports school will suffer certain impacts. In addition, other aspects should be improved at the same time, such as to increase the investment, and to improve the salary and social benefits of teachers [9]. Besides, based on this, the concept of efficiency should be attached importance to and the existing wage patterns and modes of distribution should be gradually improved to promote that the actual situation with the development of sports schools match with the construction better.

3) Establishing dynamic and reasonable flow mechanism: Sports schools must improve the existing standard of recruiting and selecting and expand the standard and approaches of recruiting and selecting, to recruit talents from a wide area. In terms of employment, the schools should gradually strengthen the mobility and openness, so that teachers can establish better communication with the external environment in the flow and open policies, such as information and teachers and so on. In the construction of teaching staff in sports schools, teachers should not only pay attention to the solid structure of the teaching staff and the coordination of resource allocation, but also focus on introducing talents in the development of sports schools, so that the schools can ensure that the teaching staff is dynamic and open. Only in this way, can the schools ensure that sports schools can more efficiently and reasonably carry out humanistic education. Therefore, the mechanism of survival of the fittest should be established to avoid redundant personnel. Only through competition and survival of the fittest, can teachers and coaches maintain high quality and high level.

\section{SUMMARY}

Humanistic management is to take people as the main objects and the most important resources of management and it respects the human values as well as fully develops people's potential to seek the free and all-round development as the ultimate goal, to promote people's value. Sports schools adhere to the people-oriented concept, and they base on not only the young athletes, but also the teachers and coaches. Only the high-quality teaching staff is formed, can the schools' quality be improved and the quality of personnel training be strengthened so that the schools can continuously develop in the fierce competition.

\section{ACKNOWLEDGMENT}

This work was supported in part by the Project of the Fundamental Research Funds for the Central Universities under Grant LGZD201709, in part by the Project of China Postdoctoral Science Foundation under Grant 2017M611849, in part by Jiangsu Qing LAN Project under Grant 2017, and in part by Nanjing Forest police College Teaching Reform Project under Grant ZD17001 \& YB17001.

\section{REFERENCES}

[1] Liu Yibing, Chang Ning, "Construction of teacher education integrated teacher team and its innovative practice," Educational Research, vol. 35, pp. 121-124, August 2015. (In Chinese) 
[2] Shi Shilong, Liu Jing, Gao Gang, "Reflection on Transformation Development in Literacy Education of Young Athletes in Guangdong Province," Journal of Guangzhou Sport University, vol. 35, pp. 113117, January 2015. (In Chinese)

[3] Zhang Hongzhen, Zhang Ruilin, Liang Shu, "Dilemmas in teenage sports development in China and their countermeasures," Journal of Physical Education, vol. 22, pp. 59-62, May 2015. (In Chinese)

[4] Chen Yuhui, "Exploration of the construction of teaching staff based on project teaching taking the Performing Arts major in higher vocational education as an example," Higher Education Exploration, vol. 21, pp. 104-106, June 2016. (In Chinese)

[5] TU Sanguang, "Three Paths for Chinese Vocational Education Teachers Team Construction," Teacher Education Research, vol. 27, pp. 99-106, March 2015. (In Chinese)
[6] Liu Yu, "Faculty Development of Higher Vocational Colleges: Status,Problems and Countermeasures," China Higher Education Research, vol. 31, pp. 79-82, January 2015. (In Chinese)

[7] Li Honglang, Li Xiao, "Reflections on the construction of Vocational Teachers' team for teachers' professional development," Vocational \& Technical Education Forum, vol. 34, pp. 71-74, December 2016. (In Chinese)

[8] Li Weihua, "Construction of teachers' team in Higher Vocational Colleges from the perspective of collaborative innovation,"Education and Vocation, vol. 45, pp. 58-60, July 2016. (In Chinese)

[9] Tian Zhen, Lin Jing, Yang Xiuli, "A study on the construction of innovative teachers in secondary vocational schools,"Chinese Vocational and Technical Education, vol. 45, pp. 94-96, July 2016. (In Chinese) 